\title{
MODAL INTELEKTUAL DALAM PENGEMBANGAN EKONOMI KREATIF: STUDI KASUS PADA SENTRA KERAJINAN SEPATU CIBADUYUT BANDUNG
}

\author{
Yuhana Astuti ${ }^{1}$ dan Annisa Anggraini \\ Fakultas Ekonomi dan Bisnis, Universitas Telkom \\ 1yuhana@telkomuniversity.ac.id
}

\section{ABSTRACT}

The concept of Creative Economy is a concept in a new economic era which intensifies on information and creativity, by relying on the ideas and the stock of knowledge of Human Resources, as a major production factor in their economic activities. This case study aims not only to determine how is the image of the intellectual capital (IC) in Cibaduyut shoe craft centers in Bandung-Indonesia but also to find the appropriate alternative strategy that can be applied by SMEs in shoe Cibaduyut shoe craft centers in order to compete in the ASEAN Economic Community by 2015. The data collection technique is using triangulation and self assessment by using ICS (Intellectual Capital Statement) as an instrument that used to define the factors of IC, then evaluate it with QQS (Quality, Quantity, Systemetic) assessment and analysis with management IC portfolio. The results showed: (1). There are three additional of IC components in SMEs of Cibaduyut Shoes Centers Bandung, such as the skills, technology, and patents, (2). IC Human Capital is a weakness of SMEs Cibaduyut shoe craft centers while IC Relational Capital is the strength. As for to gain sustainable development of creative economy, it need to focus on the development of human capital.

Keywords: Creative economy, intellectual capital, SMEs, Bandung

\section{PENDAHULUAN}

Indonesia adalah negara kepulauan tropis terbesar yang memiliki kekayaan alam dan hayati yang luar biasa menakjubkan. Semua kekayaan alam yang di miliki oleh Indonesia akan habis jika tidak mampu dikelola secara berkelanjutan. Ekonomi kreatif merupakan sektor yang dapat mengkolaborasikan seluruh kekayaan yang dimiliki oleh Indonesia secara berkelanjutan. Kreativitas akan mendorong inovasi yang menciptakan nilai tambah yang lebih tinggi dari sumber daya alam yang ada. Total jumlah usaha di Indonesia yang bergerak dalam industri kreatif sangatlah besar, dan sebagian besar adalah UKM, yaitu pada tahun 2013 mencapai 5,4 juta dan merupakan lapangan usaha terbesar ke-3 di bawah sector pertanian, peternakan, kehutanan, dan perikanan (31 juta), serta perdagangan hotel dan restoran (10 juta). Dari 15 subsektor ekonomi kreatif, sebagian besar usaha kreatif bergerak di subsektor kuliner (3juta), mode ( 1,1 juta) dan kerajinan ( 1 juta). (Kementerian Pariwisata dan Ekonomi Kreatif, 2014). 
JURNAL

MANAJEMEN

INDONESIA

Vol. 15 - No.2

Agustus 2015
Keberadaan UKM menjadi perhatian baik oleh pemerintah pusat maupun pemerintah daerah. Perhatian khusus terhadap UKM tidak terlepas dari perannya dalam pembangunan perekonomian, ketenagakerjaan dan kesejahteraan masyarakat. Selain itu, keberadaan UKM terbukti tahan uji mengadapi krisis, baik pada krisis ekonomi tahun 1998 maupun krisis global tahun 2008 (Dinas KUMKM Jawa barat, 2012).

Terkait dengan era pasar keuangan bebas, peningkatan kompetensi UKM perlu dilakukan agar UKM Indonesia siap menghadapi persaingan bisnis (Hendry, 2013). Beberapa penelitian telah mempelajari elemen-elemen kunci untuk kesuksesan dan besarnya hambatan yang dihadapi UKM (Bank Indonesia, 2011). Salah satu pendekatan yang dibutuhkan oleh UKM dalam menghadapi persaingan bisnis adalah pendekatan Intellectual Capital (IC) yang terdiri atas Human Capital (HC), Organizational Capital (OC), dan External Capital (EC), dan menjadi penentu utama keberhasilan UKM (Loureiro dan Pedro, 2012). IC merupakan pendekatan yang penting dalam menciptakan keunggulan bersaing dan sebagai menjadi penentu utama keberhasilan UKM, namun mendefinisikan IC dalam bisnis adalah sesuatu yang sulit (Daou, 2014). IC muncul sebagai suatu kegiatan yang sangat kompleks dan dinamis, merangkul pengalaman, sejarah, budaya, proses, pemahaman, interaksi, interpretasi, rutinitas, informasi, data dan pengetahuan (Jurezak, 2008). Terdapat perubahan cukup besar terhadap para pengusaha, yaitu pergeseran perekonomian dari basis keuangan kepada modal intelektual (Maditinos et al, 2009). Pengetahuan tidak lagi hanya sebagai faktor produksi, namun pengetahuan adalah faktor penting dalam kegiatan produksi itu sendiri (Scaborough, 2009).

Mengevaluasi IC pada bisnis menjadi salah satu hal yang paling penting dan merupakan topik yang relevan dalam strategi manajemen yang baru (Molodehik et $a l, 2012$ ). Mengukur IC sangat penting untuk melakukan perbandingan terhadap perusahaan yang berbeda, untuk memperkirakan nilai riil perusahaan atau bahkan untuk mengontrol perbaikan-perbaikan yang dapat dilakukan perusahaan setiap tahunnya, melakukan pengukuran terhadap IC dapat meningkatkan cara perusahaan dalam mengelola sumber daya intelektual, yang dapat menghasilkan nilai dan memberikan keuntungan maksimal bagi perusahaan.

BPS Jawa Barat menunjukkan UKM di Jawa Barat mencapai 8, 7 juta pelaku usaha yang tersebar di seluruh sektor ekonomi dan memberikan kontribusi yang cukup besar terhadap PDRB Jawa Barat yaitu sekitar 54,20\%. Hal tersebut menunjukkan bahwa potensi UKM di Jawa Barat sangat krusial dalam menunjang perekonomian regional Jawa Barat (Dinas UMKM Jawa Barat, 2014). Untuk memanfaatkan potensi tersebut, oleh karenanya UKM pada Sentra Kerajinan Sepatu Cibaduyut sebagai salah UKM yang turut berperan dalam perkembangan UKM di Jawa Barat, perlu untuk melakukan peningkatan standarisasi kualitas dan mutu produksi untuk meningkatkan keunggulan bersaingnya, khususnya dalam menghadapi Masyarakat Ekonomi ASEAN 2015. Penelitian ini bertujuan untuk mengetahui gambaran Intellectual Capital dan posisi komponennya (IC management portofolio) pada sentra kerajinan sepatu Cibaduyut Bandung, sehingga nantinya Sentra Kerajinan Sepatu Cibaduyut dapat memberikan kontribusi maksimal terhadap perekonomian regional Jawa Barat. 
Intellectual Capital (IC) berdasarkan perspektif akuntansi didefinisikan sebagai selisih antara nilai pasar dan nilai buku perusahaan Sementara itu, dari sudut pandang manajemen, IC dipandang sebagai sumber daya yang menciptakan nilai dan memastikan keunggulan kompetitif bagi organisasi. IC adalah semua tentang apa yang perusahaan harus lakukan jika perusahaan menginginkan kemenangan. IC terdiri dari tiga komponen yaitu: Human Capital, Structural Capital dan Customer Capital. Kemudian hal tersebut dipertegas oleh Bontis (1998), Tovstiga dan Tulugrova (2009), Bezhani (2010) yang mengatakan bahwa IC terdiri dari Human Capital, Structural Capital dan Relational Capital (Hendry, 2013). Relational Capital atau Customer Capital, merupakan komponen Intellectual Capital yang memberikan nilai secara nyata. Relational Capital merupakan hubungan yang harmonis yang dimiliki oleh perusahaan dengan para mitranya, baik yang berasal dari para pemasok yang ada dan berkualitas, berasal dari pelanggan yang loyal dan merasa puas akan pelayanan perusahaan yang bersangkutan, berasal dari hubungan perusahaan dengan pemerintah maupun dengan masyrakat sekitar. Hubert Saint Onge memberikan definisi Customer Capital sebagai kedalaman (penetrasi), kelebaran (cakupan) dan keterkaitan (loyalitas) dari perusahaan (Moeheriono, 2012)

\subsection{Ekonomi Kreatif}

Ekonomi kreatif merupakan kegiatan yang terkait pada kreativitas individu, keterampilan dan bakat, dan memiliki potensi kekayaan serta penciptaan lapangan kerja (Roodhouse, 2011). Selain itu, Ekonomi kreatif merupakan pengembangan ekonomi yang bernilai ekonomis yang memusatkan pada pengembangan ide dalam menghasilkan nilai tambahnya, berdasarkan kepada keterampilan, kreatifitas dan bakat individu. Dalam rangka menciptakan lapangan pekerjaan dan mengatasi kemiskinan di Indonesia diperlukan pengembangan ekonomi kreatif. Pengembangan ekonomi kreatif banyak di tentukan oleh perkembangan industri-industri kreatif ditanah air, salah satunya adalah Sentra Kerajinan Sepatu Cibaduyut. Untuk mengembangkan ekonomi kreatif dibutuhkan kolaborasi antara berbagai aktor yang berperan dalam industri kreatif tanpanya dikhawatirkan pengembangan ekonomi kreatif (Lemhanas, 2012). 


\subsection{Metodologi}

JURNAL

MANAJEMEN INDONESIA

Vol. 15 - No.2

Agustus 2015
Penelitian ini menggunakan metode kualitatif-kuantitatif dengan menggunakan data primer dan sekunder. Pengambilan sampel sumber data yang dipilih secara purposive dan besifat snowball sampling. Menggunakan tujuh narasumber sebagai informan untuk diwawancarai dan empat pelaku usaha yang melakukan self assesment. Teknik pengumpulan data yakni trianggulasi dan self assesment. Tool yang digunakan untuk menggambarkan dan mengevaluasi IC adalah Intellectual Capital Statement (ICS). ICS adalah instrumen untuk menilai, melaporkan dan mengembangkan Intellectual Capital (IC) dari sebuah organisasi (European Commision, 2010). Pada prinsipnya terdiri dari lima tahapan yakni: tahap 0 (prearrangement), tahap 1 (business model), tahap 2 (IC analysis) terdiri dari beberapa bagian yakni mendefinisikan IC, penilaian Quantity, Quality and Sistematic (QQS) dan melakukan impact analysis, tahap 3 (measurement), tahap 4 (refinement and measures) dibagi kedalam dua bagian yakni: mengintrepretasikan hasil seperti analisis kekuatan dan kelemahan, analisis dampak, dan IC management portofolio dan tahap 5 (final ICS document).

Faktor IC terdiri dari Human Capital terdiri atas professional competence, social competence, employee motivation, leadership ability. Structural Capital meliputi: corporate culture, internal co-operation and knowledge transfer, management instrument, information system and explicit knowledge, product innovation dan process optimisation and innovation. Relational capital meliputi customer relationship, supplier relationship, public relationship, investor relationship dan relationships to co-operation partners. Kelima belas faktor tersebut berdasarkan ICS-Germany dan InCaS' projects yang mencakup $80-90 \%$ faktor yang relevan bagi keberhasilan bisnis UKM (Mertin, 2009).

\section{HASILDAN PEMBAHASAN}

Berdasarkan analisis data yang bersumber dari wawancara, observasi dan dokumentasi diperoleh tiga faktor IC tambahan yaitu keterampilan, teknologi dan hak paten. Sehingga diperoleh delapan belas faktor IC pada Sentra Kerajinan Sepatu Cibaduyut yang digunakan dalam penelitian ini.

\subsection{Human Capital}

Human Capital (HC) menggambarkan faktor manusia dalam organisasi, kecerdasan gabungan, keterampilan dan keahlian yang memberikan organisasi karakter yang berbeda (Amstrong, 2010). Human Capital sebagai modal manusia yang merupakan lifeblood dalam Intellectual Capital (Moeheriono, 2012)

Berdasarkan hasil wawancara terdapat lima faktor yang menjadi komponen Human Capital. Untuk selanjutnya faktor-faktor tersebut di evaluasi menggunakan QQS assesment. Adapun hasil QQS assesment untuk faktor Human Capital pada Sentra Kerajinan Sepatu Cibaduyut dapat dilihat pada tabel 1 berikut ini. 


\begin{tabular}{|l|l|c|c|c|c|c|}
\hline Kode & \multicolumn{1}{|c|}{$\begin{array}{c}\text { Faktor } \\
\text { Human Capital }\end{array}$} & $\begin{array}{c}\text { Quantity } \\
\text { (\%) }\end{array}$ & $\begin{array}{c}\text { Quality } \\
\text { (\%) }\end{array}$ & $\begin{array}{c}\text { Systematic } \\
\text { (\%) }\end{array}$ & $\begin{array}{c}\text { Mean Value } \\
\text { (\%) }\end{array}$ & $\begin{array}{c}\text { Improvement } \\
\text { Value } \\
\text { (\%) }\end{array}$ \\
\hline HC-1 & Keterampilan & 57,50 & 59,00 & 51,5 & 56,00 & 44,00 \\
\hline HC-2 & $\begin{array}{l}\text { Profesional } \\
\text { competence }\end{array}$ & 27,25 & 26,50 & 25,00 & 26,25 & 73,75 \\
\hline HC-3 & Social competence & 51,25 & 48,75 & 51,25 & 50,42 & 49,58 \\
\hline HC-4 & $\begin{array}{l}\text { Employee } \\
\text { motivation }\end{array}$ & 49,00 & 46,25 & 41,25 & 45,50 & 54,50 \\
\hline HC-5 & Leadership ability & 45,75 & 47,50 & 43,75 & 45,67 & 54,33 \\
\hline
\end{tabular}

Tabel 1 menunjukkan hasil QQS assesment pada Sentra Kerajinan Sepatu Cibaduyut. Mean value menggabungkan quantity, quality dan management systematic kedalam satu nilai yang bertujuan untuk menemukan kekuatan dan kelemahan pada faktor IC. Nilai mean value rendah dan improvement value tinggi menunjukkan kelemahan. Sementara itu, nilai mean value tinggi dan improvement value rendah menunjukkan kekuatan. Berdasarkan hal tersebut faktor IC yakni keterampilan (HC-1) dan social competence ( $\mathrm{HC}-3)$ diidentifikasi sebagai kekuatan pada Sentra Kerajinan Sepatu Cibaduyut, karena memiliki nilai mean value tertinggi dan improvement value terendah. Sementara itu, diidentifikasi sebagai kelemahan terbesar yakni faktor IC profesional competence (HC-2).

Hasil penelitian ini sejalan dengan beberapa penelitian Bontis (1998) dan Scarborough et al (2009) yang mengungkapkan dalam salah satu faktor IC human capital, yakni keterampilan. Adanya keterampilan tersebut pada faktor IC di Kerajinan Sepatu Cibaduyut ini dikarenakan oleh proses pembuatan sepatu kulit yang menjadi ciri khas sentra menggunakan teknik handmade.

Penilaian terhadap quality tinggi menunjukkan tidak ada masalah quality pada faktor IC keterampilan saat ini pada Sentra Kerajinan Sepatu Cibaduyut. Namun, quantity faktor IC keterampilan lebih rendah dibandingkan qualitynya dan management systematic faktor IC keterampilan paling rendah dibandingkan quality dan quantitynya, sehingga terdapat resiko quality menurun di masa yang akan datang apabila tindakan management yang systematic tidak dilaksanakan, seperti langkah-langkah perbaikan dan peningkatan. Pada Sentra Kerajinan Sepatu Cibaduyut perlu melakukan pengamatan dan memberikan perhatian dimasa depan terhadap quantity dan tindakan manajemen yang sistematik pada faktor IC keterampilan untuk

\subsection{Structural Capital}

Structural Capital (SC) terdiri atas proses, peranti lunak, hak paten, hak cipta, dan kemungkinan terpenting yakni pengetahuan dan pengalaman orang didalam perusahaan (Scarborough, 2009). Pendapat lain mengatakan, SC terdiri dari aset tidak berwujud yang tergabung dalam perusahaan meliputi struktur organisasi, infrastruktur dan teknologi dan organizational capital juga disebut sebagai Structural Capital (Mertins, 2009). Berdasarkan hasil wawancara terdapat delapan faktor yang menjadi komponen Structural Capital. Untuk selanjutnya faktor-faktor tersebut di evaluasi menggunakan QQS assesment. Adapun hasil QQS assesment untuk Faktor Structural Capital pada Sentra Kerajinan Sepatu Cibaduyut dapat dilihat pada tabel 2 berikut ini. 
JURNAL

MANAJEMEN

INDONESIA

Vol. 15 - No.2

Agustus 2015

Tabel 2.

Quantity, Quality,

Systematic (QQS)

Assesment

Faktor Struktural

Capital

Sumber:

Data yang telah diolah

Tabel 3.

Quantity, Quality,

Systematic (QQS)

Assesment

Faktor Relational Capital

Sumber:

Data yang telah diolah

\begin{tabular}{l|l|c|c|c|c|c|}
\hline $\begin{array}{c}\text { Kod } \\
\text { e }\end{array}$ & \multicolumn{1}{|c|}{\begin{tabular}{c}
\multicolumn{1}{|c|}{ Faktor } \\
Structural Capital
\end{tabular}} & $\begin{array}{c}\text { Quanti } \\
\text { ty } \\
(\%)\end{array}$ & $\begin{array}{c}\text { Qualit } \\
\boldsymbol{y} \\
(\%)\end{array}$ & $\begin{array}{c}\text { Systemat } \\
\text { ic } \\
(\%)\end{array}$ & $\begin{array}{c}\text { Mean } \\
\text { Value } \\
(\%)\end{array}$ & $\begin{array}{c}\text { Improveme } \\
\text { nt Value } \\
(\%)\end{array}$ \\
\hline SC-1 & Corporate culture & 41,25 & 43,75 & 49,00 & 44,67 & 55,33 \\
\hline & $\begin{array}{l}\text { Internal co-operation and knowledge } \\
\text { SC-2 }\end{array}$ & 52,50 & 50,00 & 47,50 & 50,00 & 50,00 \\
\hline SC-3 & Management instrument & 53,75 & 51,50 & 48,75 & 51,33 & 48,67 \\
\hline SC-4 & Information sytem & 47,50 & 46,25 & 45,75 & 46,50 & 53,50 \\
\hline SC-5 & Teknologi & 52,00 & 50,00 & 50,00 & 50,67 & 49,33 \\
\hline SC-6 & Product innovation & 47,50 & 53,25 & 47,50 & 49,42 & 50,58 \\
\hline SC-7 & Process innovation & 51,25 & 50,00 & 45,00 & 48,75 & 51,25 \\
\hline SC-8 & Hak paten & 48,25 & 46,25 & 42,50 & 45,67 & 54,33 \\
\hline
\end{tabular}

Tabel 2 menunjukkan hasil QQS assesment pelaku usaha pada Sentra kerajinan Sepatu Cibaduyut pada faktor IC yang terlihat. Management Instrument (SC-3) dan Teknologi (SC-5) diidentifikasi sebagai kekuatan pada Sentra Kerajinan Sepatu Cibaduyut, karena memiliki nilai mean value tertinggi dan improvement value terendah. Sementara itu, diidentifikasi sebagai kelemahan terbesar yakni faktor Corporate Culture (SC-1), Hak Paten (SC-8), dan Information System (SC-4).

3.3. Relational Capital atau Customer Capital, merupakan komponen Intellectual Capital yang memberikan nilai secara nyata. Relational Capital merupakan hubungan yang harmonis yang dimiliki oleh perusahaan dengan para mitranya, baik yang berasal dari para pemasok yang ada dan berkualitas, berasal dari pelanggan yang loyal dan merasa puas akan pelayanan perusahaan yang bersangkutan, berasal dari hubungan perusahaan dengan pemerintah maupun dengan masyrakat sekitar. Hubert Saint Onge memberikan definisi Customer Capital sebagai kedalaman (penetrasi), kelebaran (cakupan) dan keterkaitan (loyalitas) dari perusahaan (Moeheriono, 2012). Adapun hasil QQS assesment untuk Faktor Relational Capital pada Sentra Kerajinan Sepatu Cibaduyut dapat dilihat pada tabel 3 berikut ini.

\begin{tabular}{|l|l|c|c|c|c|c|}
\hline Kode & \multicolumn{1}{|c|}{$\begin{array}{c}\text { Faktor } \\
\text { Relational Capital }\end{array}$} & $\begin{array}{c}\text { Quantity } \\
\text { (\%) }\end{array}$ & $\begin{array}{c}\text { Quatity } \\
\text { (\%) }\end{array}$ & $\begin{array}{c}\text { Systematic } \\
\text { (\%) }\end{array}$ & $\begin{array}{c}\text { Mean } \\
\text { Value } \\
\text { (\%) }\end{array}$ & $\begin{array}{c}\text { Improvement } \\
\text { Value } \\
\text { (\%) }\end{array}$ \\
\hline RC-1 & Customer relationship & 52,50 & 53,75 & 50 & 52,08 & 47,92 \\
\hline RC-2 & Supplier relationship & 47,50 & 46,25 & 43,75 & 45,83 & 54,17 \\
\hline RC-3 & $\begin{array}{l}\text { Relationships to co- } \\
\text { operation partners }\end{array}$ & 43,75 & 47,50 & 43,75 & 45,00 & 55,00 \\
\hline RC-4 & Public relationship & 50,00 & 50,00 & 49,50 & 49,83 & 50,17 \\
\hline RC-5 & Hubungan dengan Bank & 53,75 & 47,50 & 47,50 & 49,58 & 50,42 \\
\hline
\end{tabular}

Tabel 3 menunjukkan hasil QQS assesment pada faktor Relational Capital. Berdasarkan tabel tersebut faktor IC yakni Customer Relationship (RC1) diidentifikasi sebagai kekuatan terbesar pada Sentra Kerajinan Sepatu Cibaduyut, karena memiliki nilai mean value tertinggi dan improvement value terendah. Sementara itu, diidentifikasi sebagai kelemahan relationships to cooperation partners (RC-3) dan supplier relationship (RC-2). 
Gambar 1 dibawah ini menunjukkan bar chart komponen IC berdasarkan hasil summary QQS assesment faktor IC. Ditunjukkan bahwa kekuatan komponen IC pada Sentra Kerajinan Sepatu Cibaduyut yakni relational capital. Sementara itu, komponen IC yang menunjukkan kelemahan yakni human capital. Faktor IC relational capital didentifikasi sebagai kekuatan komponen IC, dengan kata lain mean value menunjukkan nilai tertinggi. Mean value menggabungkan quantity, quality dan systematic kedalam satu nilai. Quantity dan quality pada komponen IC relational capital tinggi tetapi manajemen yang systematic rendah menunjukkan bahwa tidak ada masalah saat ini, tetapi ada risiko quantity dan quality menurun dimasa depan jika tindakan management yang systematic tidak dilaksanakan seperti melaksanakan tindakan-tindakan perbaikan, peningkatan dan pengelolaan terhadap faktor-faktor IC yang terlibat didalamnya. Faktor IC Human Capital diidentifikasi sebagai kelemahan komponen IC, dengan kata lain mean value menunjukkan nilai terendah. Hal ini mungkin diakibatkan beberapa faktor IC yang menunjukkan kelemahan

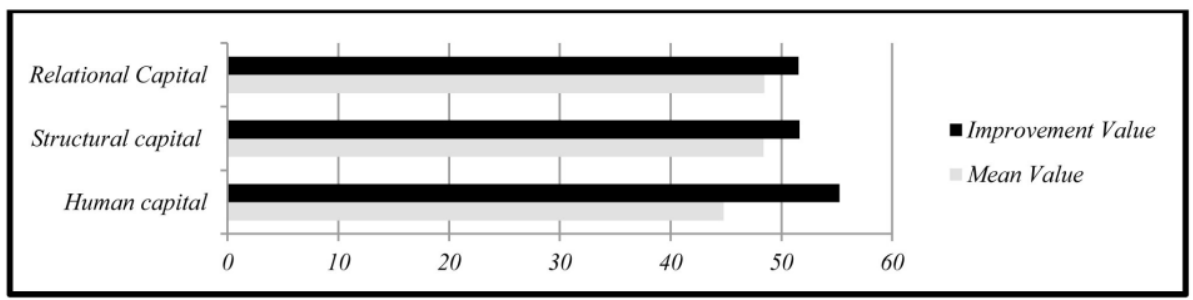

Namun secara umum, quantity dan quality pada komponen IC Human Capital tinggi, tetapi tindakan management yang systematic rendah menunjukkan bahwa tidak ada masalah saat ini, tetapi ada risiko quantity dan quality menurun dimasa depan jika management yang systematic tidak dilaksanakan seperti melaksanakan tindakan-tindakan perbaikan, peningkatan dan pengelolaan. Pelaku UKM pada Sentra Kerajinan Sepatu Cibaduyut perlu melakukan peninjauan terhadap faktor-faktor IC yang menunjukkan kekuatan dan kelemahan, untuk kemudian melakukan langkahlangkah dan tindakan yang tepat.

\subsection{Evaluasi Human Capital, Structural Capital dan Relational Capital}

Evaluasi pada masing-masing komponen IC berdasarkan QQS assesment dapat dilihat pada tabel 4 . Analisis yang menunjukkan resiko, mengidentifikasi resiko penurunan quality/quantity di masa yang akan datang apabila tindakan management yang systematic tidak dilaksanakan. Sehingga, Pelaku usaha pada Sentra Kerajinan Sepatu Cibaduyut diharapkan melakukan pengamatan dan memberikan perbaikan terkait kinerja komponen IC tersebut dimasa depan dan melaksanakan tindakan management yang systematic untuk mencapai tujuan strategis bisnis pada Sentra Kerajinan Sepatu Cibaduyut. Sementara itu, analisis potensi masalah dapat diselesaikan disebabkan terlaksananya tindakan management yang systematic, namun pelaku usaha pada Sentra Kerajinan Sepatu Cibaduyut juga perlu melakukan pemeriksaan apakah kegiatan penyelesaian masalah di masa depan akan terkendala quality/quanty apabila tidak ada tindakan peningkatan saat ini.
JURNAL

MANAJEMEN

INDONESIA

Vol. 15 - No.2

Agustus 2015

Gambar 1.

Bar chart Komponen IC

Sumber:

Data yang telah diolah 
JURNAL

MANAJEMEN

INDONESIA

Vol. 15 - No.2

Agustus 2015

Tabel 4.

Evaluasi pada

Masing-Masing

Faktor IC

berdasarkan

QQS Assesment

Sumber:

Data yang

telah diolah

\begin{tabular}{|c|c|c|c|}
\hline Kode & Evaluasi & Analisis & Saran \\
\hline \multicolumn{4}{|c|}{ Human Capital } \\
\hline $\mathrm{HC}-1$ & $\begin{array}{l}\text { Systematic } \\
\text { rendah }\end{array}$ & Risiko & Melakukan pengamatan dan tindakan \\
\hline $\mathrm{HC}-2$ & $\begin{array}{l}\text { Systematic } \\
\text { rendah }\end{array}$ & Risiko & Melakukan pengamatan dan tindakan \\
\hline $\mathrm{HC}-3$ & Quality rendah & $\begin{array}{l}\text { Potensi masalah dapat } \\
\text { diselesaikan }\end{array}$ & $\begin{array}{l}\text { Memeriksa apakah kegiatan penyelesaian } \\
\text { masalah terkendala quality. }\end{array}$ \\
\hline $\mathrm{HC}-4$ & $\begin{array}{l}\text { Systematic } \\
\text { rendah }\end{array}$ & Risiko & Melakukan pengamatan dan tindakan \\
\hline $\mathrm{HC}-5$ & $\begin{array}{l}\text { Systematic } \\
\text { rendah }\end{array}$ & Risiko & Melakukan pengamatan dan tindakan \\
\hline \multicolumn{4}{|c|}{ Structural Capital } \\
\hline SC-1 & Quantity rendah & $\begin{array}{l}\text { Potensi masalah dapat } \\
\text { diselesaikan }\end{array}$ & $\begin{array}{l}\text { Memeriksa apakah kegiatan penyelesaian } \\
\text { masalah terkendala quantity. }\end{array}$ \\
\hline SC-2 & $\begin{array}{l}\text { Systematic } \\
\text { rendah }\end{array}$ & Risiko & Melakukan pengamatan dan tindakan \\
\hline SC-3 & $\begin{array}{l}\text { Systematic } \\
\text { rendah }\end{array}$ & Risiko & Melakukan pengamatan dan tindakan \\
\hline SC-4 & Quality rendah & $\begin{array}{l}\text { Potensi masalah dapat } \\
\text { diselesaikan }\end{array}$ & $\begin{array}{l}\text { Memeriksa apakah kegiatan penyelesaian } \\
\text { masalah terkendala quality. }\end{array}$ \\
\hline SC-5 & $\begin{array}{l}\text { Systematic dan } \\
\text { quality rendah }\end{array}$ & Risiko & Melakukan pengamatan dan tindakan \\
\hline SC-6 & $\begin{array}{l}\text { Quantity dan } \\
\text { systematic } \\
\text { rendah }\end{array}$ & Risiko & Melakukan pengamatan dan tindakan \\
\hline SC-7 & $\begin{array}{l}\text { Systematic } \\
\text { rendah }\end{array}$ & Risiko & Melakukan pengamatan dan tindakan \\
\hline SC-8 & $\begin{array}{l}\text { Systematic } \\
\text { rendah }\end{array}$ & Risiko & Melakukan pengamatan dan tindakan \\
\hline \multicolumn{4}{|c|}{ Relational Capital } \\
\hline RC-1 & $\begin{array}{l}\text { Systematic } \\
\text { rendah }\end{array}$ & Risiko & Melakukan pengamatan dan tindakan \\
\hline $\mathrm{RC}-2$ & $\begin{array}{l}\text { Systematic } \\
\text { rendah }\end{array}$ & Risiko & Melakukan pengamatan dan tindakan \\
\hline $\mathrm{RC}-3$ & $\begin{array}{l}\text { Quantity dan } \\
\text { systematic } \\
\text { rendah }\end{array}$ & Risiko & Melakukan pengamatan dan tindakan \\
\hline RC-4 & $\begin{array}{l}\text { Systematic } \\
\text { rendah }\end{array}$ & Risiko & Melakukan pengamatan dan tindakan \\
\hline RC-5 & $\begin{array}{l}\text { Quality dan } \\
\text { systematic } \\
\text { rendah }\end{array}$ & Risiko & Melakukan pengamatan dan tindakan \\
\hline
\end{tabular}

Selanjutnya faktor IC yang memiliki dampak terbesar terhadap keberhasilan bisnis pada Sentra Kerajinan Sepatu Cibaduyut dapat dilihat pada tabel 5 . Faktor IC yang memiliki dampak terbesar terhadap keberhasilan bisnis adalah keterampilan dan faktor IC yang memiliki dampak terendah dalam mendukung kesuksesan bisnis pelaku usaha adalah public relationship dan relationships to co-operation partners. Keterampilan adalah faktor IC yang sangat penting dalam keberhasilan bisnis pelaku usaha, sehingga para pelaku usaha dapat memberikan perhatian kepada faktor IC keterampilan. Sementara itu, komponen IC yang sangat penting dalam kesuksesan bisnis pelaku usaha adalah Structural Capital. 


\begin{tabular}{|c|l|c|c|}
\hline Kode & \multicolumn{1}{|c|}{ Faktor IC } & Rangking Sum & Weight Score \\
\hline HC-1 & Keterampilan & 66 & $10 \%$ \\
\hline HC-2 & Profesional competence & 28 & $4 \%$ \\
\hline HC-3 & Social competence & 42 & $6 \%$ \\
\hline HC-4 & Employee motivation & 57 & $8 \%$ \\
\hline HC-5 & Leadership ability & 55 & $8 \%$ \\
\hline SC-1 & Corporate culture & 27 & $4 \%$ \\
\hline & Internal co-operation and knowledge & & \\
SC-2 & transfer & 33 & $5 \%$ \\
\hline SC-3 & Management instrument & 32 & $5 \%$ \\
\hline SC-4 & Information sytem & 37 & $5 \%$ \\
\hline SC-5 & Teknologi & 31 & $5 \%$ \\
\hline SC-6 & Product innovation & 59 & $9 \%$ \\
\hline SC-7 & Process innovation & 30 & $4 \%$ \\
\hline SC-8 & Hak paten & 37 & $5 \%$ \\
\hline RC-1 & Customer relationship & 58 & $8 \%$ \\
\hline RC-2 & Supplier relationship & 34 & $5 \%$ \\
\hline RC-3 & Relationships to co-operation partners & 15 & $2 \%$ \\
\hline RC-4 & Public relationship & 31 & $2 \%$ \\
\hline RC-5 & Hubungan dengan Bank & 684 & $5 \%$ \\
\hline & Total & & $100 \%$ \\
\hline
\end{tabular}

Vol. 15 - No.2

Agustus 2015

Tabel 5.

Rangking Sum dan Weight Score

Sumber:

Data yang telah diolah

\subsection{IC Management Portofolio}

Analisis terakhir dari analisis IC pada Sentra Kerajinan Sepatu Cibaduyut ditunjukkan dengan IC management portofolio yang menampilkan potensi masa depan faktor IC yang berbeda dalam matriks empat kuadran. Adapun IC management portofolio pada Sentra Kerajinan Sepatu Cibaduyut dapat dilihat berdasarkan gambar 2 dibawah ini.

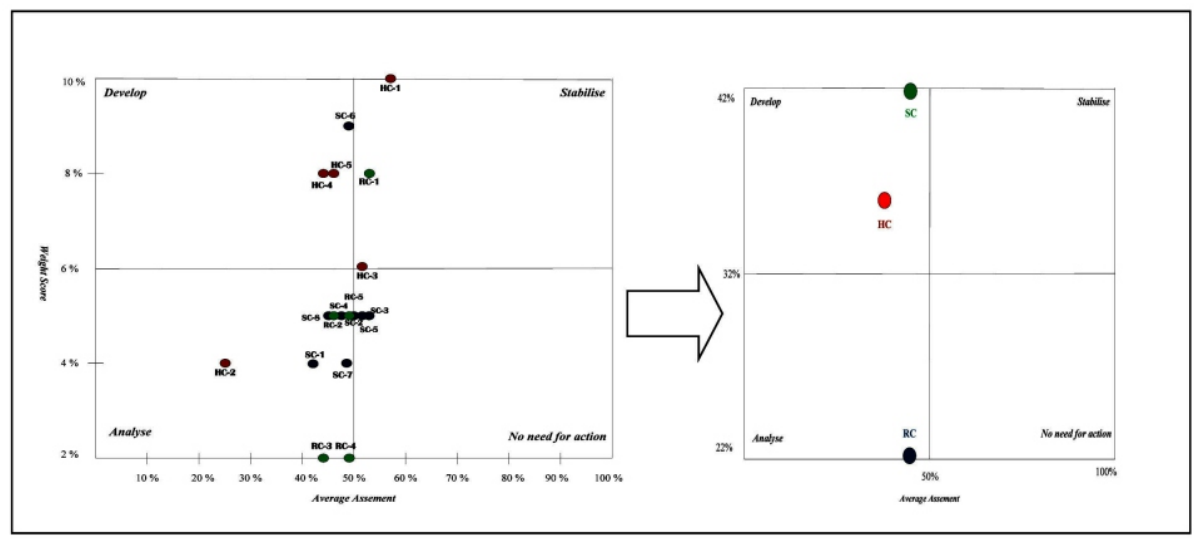

Gambar 2.

IC Mangement Portofolio

Sumber:

Data yang telah diolah 
JURNAL

MANAJEMEN

INDONESIA

Vol. 15 - No.2

Agustus 2015
Gambar 2 menunjukkan IC management portofolio. Kuadran satu (develop) menunjukkan beberapa faktor IC dengan kode SC-6, HC-5, HC-4 menandakan tingkat kepentingan terhadap faktor IC tersebut relatif tinggi dan memiliki potensi tinggi terhadap peningkatan. Untuk pelaku usaha pada Sentra Kerajinan Sepatu Cibaduyut sangat penting untuk membangun faktor IC ini di bandingkan beberapa faktor lain. Pelaku usaha dapat berinvestasi pada faktor IC, SC-6, HC-5 dan HC-5. Kuadran dua (stabilise) menunjukkan beberapa faktor IC dengan kode RC-1 dan HC-1 menandakan kepentingan terhadap faktor IC tersebut relatif tinggi namun memiliki potensi untuk peningkatan relatif rendah. Ini merupakan faktor IC yang paling baik bagi pelaku usaha di Sentra Kerajinan Sepatu Cibaduyut. Kuadran dua menunjukkan kekuatan dari pelaku usaha di Sentra Kerajinan Sepatu Cibaduyut. Untuk saat ini faktor IC dengan kode RC-1 dan HC-1 sudah dalam kondisi yang baik dan penting untuk pelaku usaha. Kuadran ketiga (no need for action) menunjukkan beberapa faktor IC dengan kode SC-5 dan SC-3 menandakan tingkat kepentingan terhadap faktor IC tersebut relatif rendah dan memiliki potensi rendah untuk peningkatan. Faktor IC ini sebagian besar sudah sangat baik dan potensi perbaikan rendah. Faktor IC ini dapat diabaikan dengan tidak melakukan tindakan apapun atau dapat melakukan sedikit tindakan. Kuadran empat (analyse) menunjukkan beberapa faktor IC dengan kode RC-3, RC-4, HC-2, SC-1, SC-7, RC-2, RC-5, SC-8 dan SC-4 menandakan tingkat kepentingan relatif rendah namun memiliki potensi tinggi terhadap peningkatan. Faktor ini memiliki sedikit pengaruh pada tujuan strategis bisnis, sehingga tindakan perbaikan secara langsung tidak di perlukan. Namun faktor IC ini perlu di analisis, seperti langkah-langkah pembangunan tertentu secara tidak langsung yang akan mempengaruhi faktor lain. IC component management portofolio. Structural Capital dan Human Capital berada pada kuadran satu (develop) dan Relational Capital berada pada kuadran empat (analyse).

\section{KESIMPULAN DAN SARAN}

Berdasarkan analisis dan pembahasan diatas dapat disimpulkan bahwa terdapat tiga komponen analisis tambahan yang diperoleh dari gambaran Intellectual Capital di Sentra Kerajinan Sepatu Cibaduyut Bandung, yaitu keterampilan, teknologi dan hak paten. Faktor IC keterampilan didentifikasi sebagai kekuatan selain itu juga memiliki dampak dan kepentingan relatif tinggi terhadap kesuksesan bisnis perusahaan. Sedangkan faktor IC profesional competence diidentifikasi sebagai kelemahan,

Adapun saran dari hasil penelitian ini adalah jika pelaku UKM di Sentra Kerajinan Sepatu Cibaduyut ingin melakukan investasi untuk mencapai kesuksesan bisnis, pelaku usaha dapat berinvestasi pada faktor IC dengan product innovation, leadership ability dan employee motivation karena faktor IC tersebut memiliki dampak dan kepentingan tinggi terhadap kesuksesan bisnis. Jika pelaku usaha ingin melakukan investasi pada komponen IC, pelaku usaha dapat berinvestasi terlebih dahulu pada komponen IC Human Capital, karena tingkat kepentingannya relatif tinggi dan potensi peningkatan dan perbaikan tinggi.

Untuk pengembangan ekonomi kreatif diperlukan dukungan pemerintah terhadap UKM selaku pelaku ekonomi kreatif, terkait dengan kelemahan-kelemahan yang ada pada Sentra Kerajinan Sepatu Cibaduyut seperti profesional competence, corporate culture, relationships to co-operation partners dan komponen IC Human Capital serta melakukan peningkatan pada faktor IC keterampilan, oleh customer relationship dan management instrument. 


\section{DAFTAR PUSTAKA}

Armstrong, Michael.2010. Armstrong's Essential Human Resource Management Practice A Guide to People Management.

Bank Indonesia. 2011. Kajian Akademik Pemeringkat Kredit Bagi Usaha Mikro, Kecil dan Menengah di Indonesia. Jakarta: Bank Indonesia

Bontis, Nick .1998. Intellectual Capital: An Exploratory Study that Develops Measures and Models. Management Decision. 36 (2). 63-76.

Cohen, et al. 2014. Intellectual Capital, Strategy and Financial Crisis from a SMEs Perspective. Journal of Intellectual Capital. 15 (2). 294-315.

Daou, Alain et al. 2014. Towards a better understanding of intellectual capital in Mexican SMEs. Journal of Intellectual Capital. 316-332.

Dinas Koperasi dan Usaha Mikro, Kecil, Menengah (KUMKM) Jawa barat.2012. Katalog Produk Unggulan Koperasi dan UMKM Jawa Barat. Jawa Barat: Dinas KUMKM.

European Commision. 2010. Incas: Intellectual Capital Statement. DG Research under the EU 6th Framework Programme

Henry, Lennox. 2013. Intellectual Capital in a Recession: Evidence from UK SMEs. Intellectual Capital. 14 (1). 84 - 101.

Jurczak, Jolanta. 2008. Intellectual Capital. Economic and Organization Of Enterprise. 37-45

Kementerian Pariwisata dan Ekonomi Kreatif Republik Indonesia. 2014. Ekonomi Kreatif: Kekuatan Baru Indonesia Menuju 2025. Jakarta

Lembaga Pertahanan Nasional Republik Indonesia. 2012. Jurnal Kajian LEMHANNAS RI Edisi 14 Desember 2012.

Loureiro dan Pedro Figueroa Dorrego. 2012. Intellectual capital and system of innovation: What really matters at innovative SMEs. Intellectual Capital. 8 (2). 239-274.

Maditinos, Dimitros et al., 2009. Intellectual Capital and Business Performance: An Empirical study. International Conference on Accounting and Finance in Transition (ICAFT). Greenwich, London: Greenwich University, The Business School.

Mertins, Kai et al., (2009). InCaS: Intellectual Capital Management in European SME - Its Strategic Relevance and the Importance of its Certification. The Electronic Journal of Knowledge Management. 7 (1). 111 - 122

Moeheriono.2012. Pengukuran Kinerja Berbasis Kinerja. Edisi Revisi. Jakarta: PT.Raja Grafindo Persada.

Molodchik, Mariya et al., 2012. Intellectual Capital Transformation Evaluating Model. Intellectual Capital. 13 (4). 444 - 461.

Roodhouse, S. 2011. The Creative Industries Definitional Discourse. (Henry, C. and de Bruin, A. (Ed.)) dalam Basuki, A. Entrepreneurship and the Creative Economy: Process, Practice and Policy: 9. Glos (UK): Edward Elgar Publishing Limited.

Pemerintah Provinsi Jawa Barat Dinas Koperasi dan Usaha Mikro, Kecil dan Menengah. Buku Profil Usaha Mikro, Kecil dan Menegah (UMKM) Jawa Barat.

Scarborough, Norman et al., 2009. Essentials of Entrepreneurship and Small Business Management. United States of America: Pearson, Prentice Hall. 
JURNAL

MANAJEMEN

INDONESIA

Vol. 15 - No.2

Agustus 2015 